Article

\title{
Synthesis of Three-Dimensional Carbon
} Nanostructure/Copper Nanowire for Additive Interface Layer of Ionic Polymer Metal Composite

\author{
Seongjun Park ${ }^{1}$, Minjeong Park ${ }^{1} \mathbb{B}$, Seonpil Kim ${ }^{2}$ and Minhyon Jeon ${ }^{1, *}$ \\ 1 Department of Nanoscience and Engineering, Center for Nano Manufacturing, Inje University, Gimhae \\ 50834, Korea; power0092@gmail.com (S.P.); mjpark9121@gmail.com (M.P.) \\ 2 Department of Military Information Science, Gyeongju University, Gyeongju 38065, Korea; seonpil@gu.ac.kr \\ * Correspondence: mjeon@inje.ac.kr; Tel.: +82-55-320-3672; Fax: +82-55-320-3963
}

Received: 30 January 2020; Accepted: 24 February 2020; Published: 28 February 2020

check for updates

\begin{abstract}
Additive interface materials for improved ionic polymer metal composite (IPMC) actuator performance are being investigated. In this study, three-dimensional carbon nanostructure/copper nanowire (3DC Cu-NW) with a novel structure was synthesized via low-pressure chemical vapor deposition. An IPMC actuator with a 3DC Cu-NW interface layer was fabricated, which exhibited improved actuation performance, long-term stability, and electrochemical properties. The proposed $3 \mathrm{DC}$ consists of carbon nanotubes (CNTs) and graphene, grown using an Fe catalyst and $\mathrm{CH}_{4}$ gas, respectively. We optimized the growth conditions (Fe catalyst: $12.5 \mathrm{mg} / \mathrm{L}, \mathrm{CH}_{4}: 20 \mathrm{sccm}$ ) to achieve a 3DC with an appropriate thickness and a large specific surface area. The 3DC Cu-NW benefited from a $\mathrm{Cu}$ oxidation prevention property and a large specific surface area. The electrochemical properties and actuation performance of the IPMC actuator improved with an increased 3DC Cu-NW concentration. An IPMC actuator with a $0.6 \mathrm{wt} \% 3 \mathrm{DC} \mathrm{Cu}-\mathrm{NW}$ interface layer exhibited 1.3- and 5.6-fold electrochemical property and actuation performance improvement, respectively, over an IPMC actuator with no 3DC Cu-NW interface layer. These results show that the proposed 3DC $\mathrm{Cu}-\mathrm{NW}$ has potential as an IPMC actuator interface material, and that 3DC Cu-NW synthesis and application technology can be applied to future research on sensor, actuator, and flexible devices.
\end{abstract}

Keywords: carbon nanotube; graphene; Cu-NW; three-dimensional carbon nanostructure; ionic polymer metal composite; additive layer

\section{Introduction}

Compared to traditional machine actuators, smart actuators have advantages such as miniaturization and simplification of structure. Piezoelectrics, ferroelectrics, shape memory alloys and electroactive polymers were activated by transforming electrical energy into mechanical energy [1-4] and $\mathrm{MoS}_{2}$, graphene, and graphene nanoplatelet-based polymer actuators have a mechanism that operates by transforming light energy into mechanical energy [5-7]. Among them, ionic polymer metal composite (IPMC) has been studied as an actuator for application in the biomedical, industrial, and medical fields, because of its advantages of low mass, flexibility, and its large bending deformation with low driving voltage [8-11]. IPMC consists of electrodes and an ionic polymer membrane. When the input voltage is supplied to IPMC electrodes, the hydrated protons in the ionic polymer is moved in cathode. Cathode with a relatively high proton concentration expand and the anode is compressed $[4,5]$ so the bending motion of the IPMC actuator can occur. If an alternating current voltage is provided, the above phenomenon repeats when voltage is applied. Recently, the interface between the electrode and ionic polymer membrane has attracted research attention, with regard to enhancing 
the actuation performance, long-term stability, and electrochemical properties of the IPMC actuator, for potential application in sensor and actuator devices. In particular, many researchers [12-18] have investigated various additives for Nafion, which is widely used in ion exchange polymers and interface layers because of features such as its chemical stability, commercial availability, thermal stability, and high proton conductivity. Metallic materials such as $\mathrm{Pt}, \mathrm{Au}$, and $\mathrm{TiO}_{2}$ nanoparticles, as well as carbon materials such as carbon nanotubes (CNTs) and graphene, have been used as additives [12-18]. However, improvements to the actuation performance, long-term stability, and electrochemical properties of the IPMC actuator are still required. Non-oxidative materials with large specific surface areas, nanowire, or nanotube structures can potentially facilitate these improvements.

Among the various nanowire materials, copper nanowire (Cu-NW) has the advantage of high electrical conductivity, superior structural flexibility, and low-cost synthesis [19]. Furthermore, $\mathrm{Cu}-\mathrm{NW}$ can constitute an alternative metal nanoparticle because of its very large or easily tunable aspect ratio and specific surface area $[20,21]$. However, $\mathrm{Cu}-\mathrm{NW}$ can have problems with electron transport and conductivity because of its low chemical stability and easy oxidation. This problem is solved by growing graphene on the $\mathrm{Cu}-\mathrm{NW}$ surface. Graphene is a smart nanomaterial with excellent electrical conductivity, electrochemical stability, and gas-impermeability [22-25]. When graphene-based composites are used in Nafion, the mechanical and electrochemical properties are enhanced, and when this material is applied to an IPMC actuator, the actuation performance is improved. Importantly, the electrochemical properties (such as the capacitance) of the graphene/CNT structure are reported to be superior to those of graphene alone [26]. Additionally, because CNTs have nanotube structures, large specific surface areas, various surface functional groups, and high strength, they can enhance the actuation performance, as well as the electrochemical properties of an IPMC actuator containing a graphene/CNT structure.

In this study, CNTs and graphene are grown on $\mathrm{Cu}-\mathrm{NW}$ using an Fe catalyst and $\mathrm{CH}_{4}$ gas in a low-pressure chemical vapor deposition (LP-CVD) system. We successfully synthesize three-dimensional carbon nanostructure/copper nanowire (3DC Cu-NW) with a new structure. Notably, application of the $\mathrm{CNT} /$ graphene onto the $\mathrm{Cu}-\mathrm{NW}$ prevents $\mathrm{Cu}$ oxidation. We then fabricate an IPMC actuator with a 3DC Cu-NW interface layer using the hot-press method. The electrochemical properties of the IPMC actuator with the 3DC Cu-NW interface layer are increased by 3DC Cu-NW with a large specific surface area, and its actuation performance is enhanced with increased 3DC $\mathrm{Cu}-\mathrm{NW}$ concentration.

\section{Materials and Methods}

\subsection{Materials}

Copper nitrate hydrate $\left(99.999 \% \mathrm{Cu}\left(\mathrm{NO}_{3}\right)_{2}\right)$, sodium hydroxide (10.0 N standardized solution, $\mathrm{NaOH}$ ), sodium hydroxide (pearl, $97 \% \mathrm{NaOH}$ ), and $\mathrm{Cu}$ foil (thickness: $0.025 \mathrm{~mm}, 99.999 \%$ ) were purchased from Sigma Aldrich, Saint Louis, MO, USA. Hydrazine solution $\left(35 \mathrm{wt} \%\right.$ in $\left.\mathrm{H}_{2} \mathrm{O}, \mathrm{N}_{2} \mathrm{H}_{4}\right)$ was purchased from Alfa Aesar, Heverville, MA, USA. These materials were used for the $\mathrm{Cu}$-NW synthesis. Iron $(\mathrm{Fe})$ nanoparticles $\left(99.5+\%, 30 \mathrm{~nm}, \mathrm{Fe}_{2} \mathrm{O}_{3}\right.$ alpha) were used as a catalyst for the CNT growth, and were purchased from RND Korea, Ltd, Gwangmyeong, Korea. A silver nanowire (Ag-NW) solution was purchased from Duksan Hi-Metal (Ulsan, Korea), and graphene oxide (GO) was purchased from Grapheneall, Ltd, Siheung, Korea. Nafion-117 and $20 \mathrm{wt} \%$ Nafion solution were purchased from the DuPont Company (Midland, MI, US), and were used as the ionic polymer membrane of the IPMC and the interface material with the $\mathrm{Cu}-\mathrm{NW}$, respectively. The cation used for the actuation of the IPMC in the Nafion was 1-Ethyl-3 methylimidazolium trifluoromethylsulfonate (EMIM-Otf, ionic liquid), and this was purchased from Merck KGaA (Darmstadt, Germany). Polyvinylidene difluoride (PVDF) membrane filter paper (pore size: $0.20 \mu \mathrm{m}$, diameter: $\phi 47 \mathrm{~mm}$ ) was purchased from Hyundai Micro., Ltd, Seongnam, Korea, and was used for $\mathrm{Cu}-\mathrm{NW}$ synthesis and fabrication of the GO/Ag-NW paper electrode. 


\subsection{Growth of the Three-Dimensional Carbon Nanostructure on Copper Nanowire (3DC Cu-NW)}

In the typical $\mathrm{Cu}-\mathrm{NW}$ synthesis process [20,21], the $\mathrm{NaOH}$ of $15 \mathrm{M}$ and $\mathrm{Cu}\left(\mathrm{NO}_{3}\right)_{2}$ of $0.1 \mathrm{M}$ were prepared before $\mathrm{Cu}-\mathrm{NW}$ synthesis, using a deionized water base solution. Then, $20 \mathrm{~mL} \mathrm{NaOH}, 1$ $\mathrm{mL} \mathrm{Cu}\left(\mathrm{NO}_{3}\right)_{2}$, and $100 \mu \mathrm{L}$ ethylenediamine (EDA) were mixed in a round flask in a $60{ }^{\circ} \mathrm{C}$ water bath. The solution was stirred at $700 \mathrm{RPM}$ for $3 \mathrm{~min}$. After stirring, 20 to $45 \mu \mathrm{L} \mathrm{N}_{2} \mathrm{H}_{4}$ was added to the solution. The stirring stopped after $2 \mathrm{~min}$. After $1 \mathrm{~h}$, the $\mathrm{Cu}-\mathrm{NW}$ floated on the surface of the solution, and its color changed from colorless to dark red. The $\mathrm{Cu}-\mathrm{NW}$ was rinsed in deionized water and harvested on a polyethersulfone (PES) membrane with a filtration process. Herein, the EDA demonstrated an anisotropic growth of Cu-NW [20,21,27]. The anisotropic-grown Cu-NW was easily obtained on the PES membrane filter paper.

Graphene/Cu-NW (G/Cu-NW) was grown using LP-CVD. The $\mathrm{Cu}-\mathrm{NW}$ was placed in a tungsten (W) boat, and the $\mathrm{W}$ boat was wrapped in $\mathrm{Cu}$ foil. The Cu-NW was annealed in an atmosphere of 200 sccm argon (Ar) and $50 \mathrm{sccm} \mathrm{H}_{2}$ at $350{ }^{\circ} \mathrm{C}$ with LP-CVD over a $15 \mathrm{~min}$ period. In the graphene growth step, the temperature gradient consisted of a $900{ }^{\circ} \mathrm{C}$ heating zone and a $650{ }^{\circ} \mathrm{C}$ growth zone. Graphene was also grown in 10 to $60 \mathrm{sccm} \mathrm{CH}_{4}$ for $10 \mathrm{~min}$. After the graphene growth process was completed, the quartz was cooled to room temperature.

Fe nanoparticles were used as a catalyst for CNT growth on the G/Cu-NW. Fe nanoparticles at a

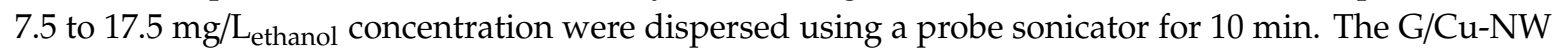
was added to the suspension and dispersed using a bath sonicator for $1 \mathrm{~min}$. After stirring for $1 \mathrm{~h}$, the Fe catalysis on the G/Cu-NW (Fe/G/Cu-NW) was harvested with a vacuum oven $\left(50{ }^{\circ} \mathrm{C}\right.$, over $1 \mathrm{~h}$ ). The CNTs were grown using LP-CVD. To remove organics, the Fe/G/Cu-NW composite was annealed at $300{ }^{\circ} \mathrm{C}$ in $1000 \mathrm{sccm} \mathrm{Ar}$, and $100 \mathrm{sccm}$ dihydrogen $\left(\mathrm{H}_{2}\right)$ for $10 \mathrm{~min}$. The temperature gradient consisted of a $700{ }^{\circ} \mathrm{C}$ heating zone and $540{ }^{\circ} \mathrm{C}$ growth zone in the CNT growth step. CNTs were also grown in $2 \mathrm{sccm}$ acetylene for $12 \mathrm{~min}$. After CNT growth, the specimens were cooled to room temperature. Hence, the 3DC Cu-NW with the new structure was successfully fabricated.

\subsection{Fabrication of the IPMC Actuator based on 3DC Cu-NW}

A GO/Ag-NW paper electrode was prepared according to the method of Yoo et al. [28]. The Nafion ion exchange process was performed following a previously reported method [29]. The 3DC Cu-NW was stirred in Nafion solution and dispersed using a bath sonicator for $10 \mathrm{~min}$. The 3DC Cu-NW/Nafion composite specimens were prepared with $0.2,0.4$, and $0.6 \mathrm{wt} \%$ 3DC Cu-NW content. The 3DC $\mathrm{Cu}-\mathrm{NW} / \mathrm{Nafion}$ composite was painted directly on the Nafion membrane. To obtain a 3DC Cu-NW interface layer between the GO/Ag-NW electrode and Nafion membrane, the GO/Ag-NW electrode was placed on both sides of the 3DC Cu-NW/Nafion composite painted on the Nafion membrane. Attachment was achieved using a hot press at $0.1 \mathrm{MPa}$ and $100{ }^{\circ} \mathrm{C}$ for $2.5 \mathrm{~min}$. The filter paper was removed using acetone solution. Finally, the IPMC actuator with the 3DC Cu-NW interface layer was cut to dimensions of $0.5 \times 4.0 \mathrm{~cm}^{2}$.

\subsection{Characteristics}

The 3DC Cu-NW morphology was investigated using field-emission scanning electron microscopy (FE-SEM; S-4300, Hitachi, Tokyo, Japan). The actuation performance of the IPMC actuator was measured using a laser displacement sensor (ZS-LD80, OMRON Korea, Seoul, Korea). Figure 1 showed the mechanical property measurement system with the laser displacement sensor of the IPMC actuator. This system was made by ourselves. The functional groups of the 3DC Cu-NW were observed using Fourier-transform infrared spectroscopy (FT-IR; FT/IR-6300, JASCO, Tokyo, Japan). The electrochemical properties of the IPMC actuator were measured using a cyclic voltammetry system (CompactStat.h10800, Ivium, Eindhoven, Netherlands). The oxidation of the Cu-NW and G/Cu-NW was observed using an X-Ray diffractometer (XRD; Ultima IV, Rigaku, Tokyo, Japan). 

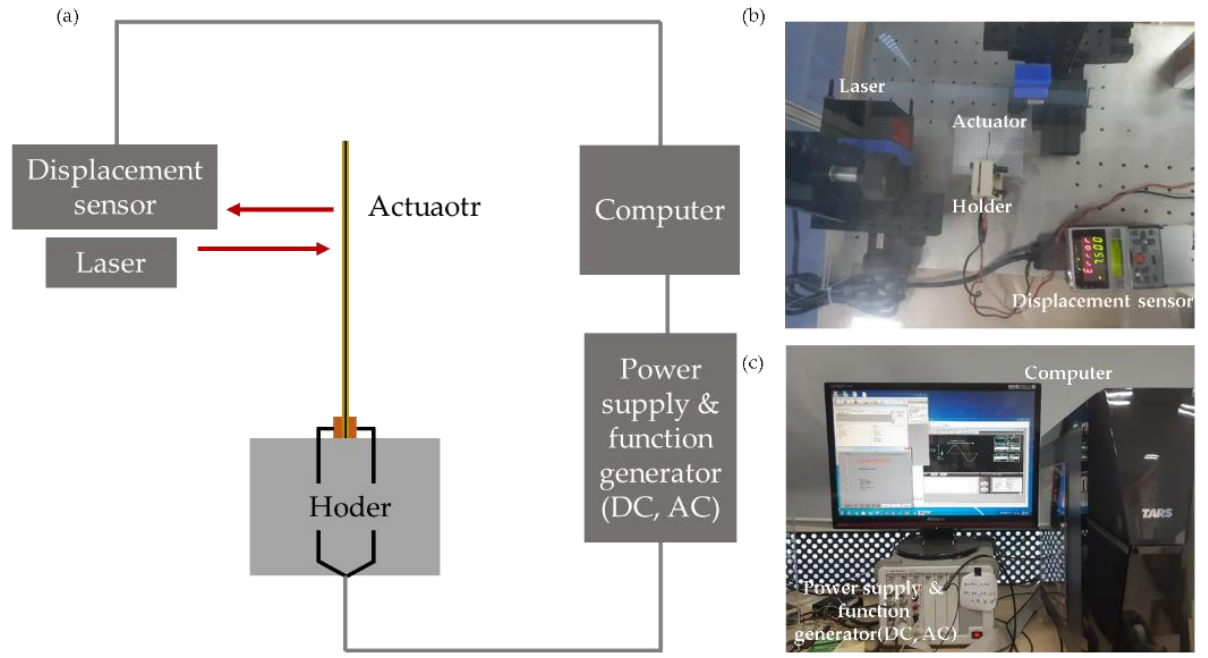

Figure 1. (a) Schematic diagram, and $(\mathbf{b}, \mathbf{c})$ photographs of actuation measurement system.

\section{Results}

\subsection{Characteristics of $3 D C \mathrm{Cu}-\mathrm{NW}$}

To synthesize $\mathrm{Cu}-\mathrm{NWs}$ with various diameters, we controlled the $\mathrm{N}_{2} \mathrm{H}_{4}$ concentration. Figure 2 shows various $\mathrm{Cu}-\mathrm{NW}$ morphologies according to the $\mathrm{N}_{2} \mathrm{H}_{4}$ concentration; the inset images show parts of individual Cu-NWs. The average Cu-NW diameter increased from 183 to $443 \mathrm{~nm}$, in accordance with increases in the $\mathrm{N}_{2} \mathrm{H}_{4}$ concentration from 20 to $45 \mu \mathrm{L}$. Particle-like surfaces were observed for the Cu-NW specimens. In particular, the $\mathrm{Cu}-\mathrm{NW}$ shape was not maintained for the $45 \mu \mathrm{L} \mathrm{N}_{2} \mathrm{H}_{4}$ concentration. For Cu-NW shape maintenance under graphene growth temperatures, $\mathrm{Cu}-\mathrm{NW}$ diameters exceeding $350 \mathrm{~nm}$ are needed. Thus, a Cu-NW specimen with a less particle-like surface, and an approximate diameter of $362 \mathrm{~nm}$, was selected for use in the graphene growth process on the Cu-NW surface; this $\mathrm{Cu}-\mathrm{NW}$ was obtained using $40 \mu \mathrm{L} \mathrm{N}_{2} \mathrm{H}_{4}$ concentration.

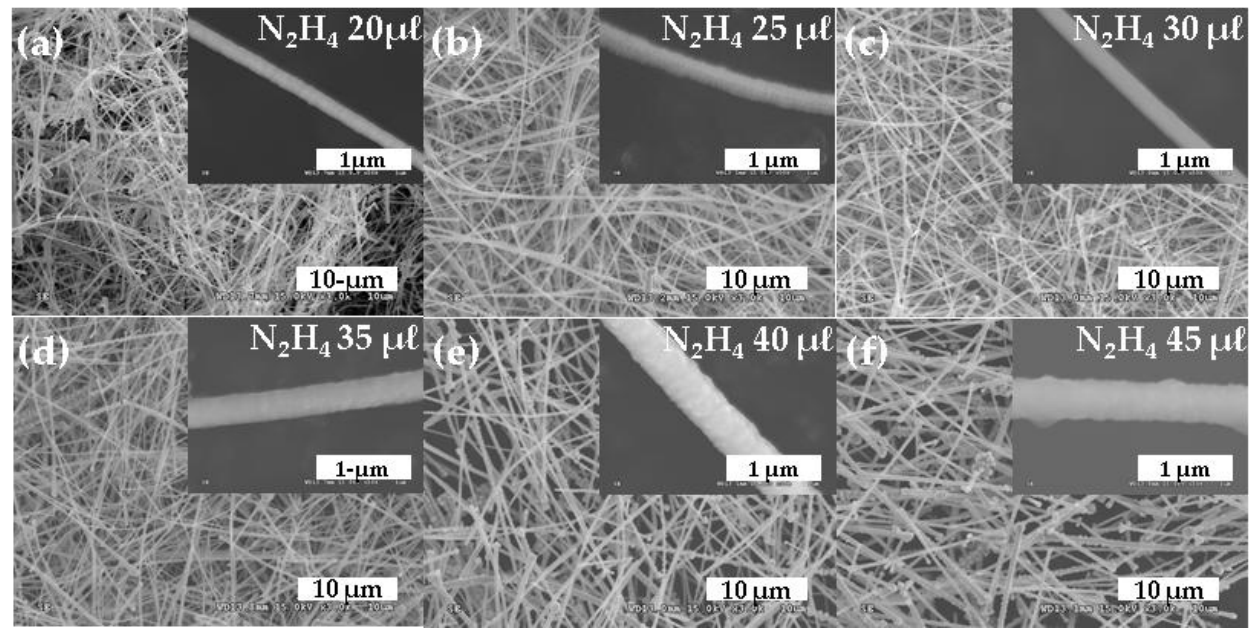

Figure 2. SEM images of Cu-NW for $\mathrm{N}_{2} \mathrm{H}_{4}$ concentrations of (a) 20, (b) 25, (c) 30, (d) 35, (e) 40, and (f) $45 \mu \mathrm{L}$.

Graphene was grown on the $\mathrm{Cu}-\mathrm{NW}$ using the methods of $\mathrm{Xu}$ et al. [24] and Park et al. [27]. These two methods were used to protect the $\mathrm{Cu}-\mathrm{NW}$ shape from the vapor pressure and heat treatment. Figure 3 shows the graphene growth achieved according to various $\mathrm{CH}_{4}$ concentrations. The various $\mathrm{G} / \mathrm{Cu}-\mathrm{NW}$ s were not melted, and their surfaces were smooth with no particle-like $\mathrm{Cu}-\mathrm{NW}$ surfaces as a result of the $\mathrm{H}_{2}$ treatment and annealing process. Furthermore, all the G/Cu-NWs had similar shapes 
regardless of the changing $\mathrm{CH}_{4}$ concentrations (Figure $3 \mathrm{~b}-\mathrm{h}$ and insets). We oxidized all the $\mathrm{G} / \mathrm{Cu}-\mathrm{NWs}$ under $80^{\circ} \mathrm{C}$ for $80 \mathrm{~h}$, so as to observe the graphene step coverage and gas impermeability. Figure $3 \mathrm{a}, \mathrm{c}, \mathrm{e}$ and $\mathrm{g}$ are optical images of the $\mathrm{Cu}-\mathrm{NW}$ specimens before and after oxidation (the specimens on the left and right of each image, respectively), for $\mathrm{CH}_{4}$ concentrations of 10, 20, 30, and $40 \mathrm{sccm}$, respectively. The G/Cu-NW obtained using $10 \mathrm{sccm} \mathrm{CH}_{4}$ changed color significantly from brown to dark brown, indicating poor step coverage of the graphene on the $\mathrm{Cu}-\mathrm{NW}$. In contrast, the $\mathrm{G} / \mathrm{Cu}-\mathrm{NW}$ s prepared using the other $\mathrm{CH}_{4}$ concentrations had even and similar colors after the oxidation process. Thus, good graphene step coverage was achieved for the $\mathrm{G} / \mathrm{Cu}-\mathrm{NW}$ specimens prepared with $\mathrm{CH}_{4}$ content of $20 \mathrm{sccm}$ or more, and the Cu-NW was not oxidized.

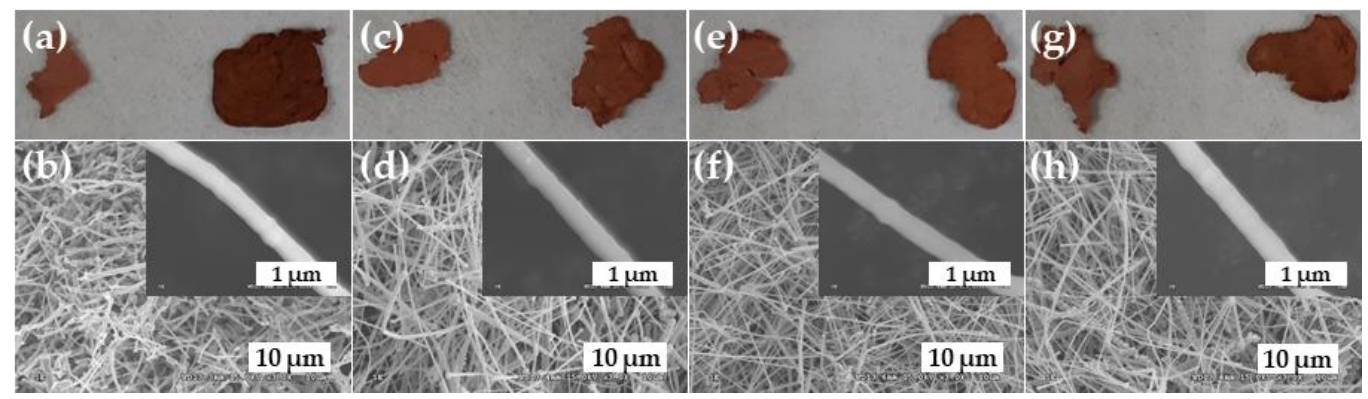

Figure 3. (a,c,e,g) Optical images of G/Cu-NW specimens before and after oxidation (specimens on left and right of each image, respectively), and $(\mathbf{b}, \mathbf{d}, \mathbf{f}, \mathbf{h})$ SEM images of $\mathrm{G} / \mathrm{Cu}-\mathrm{NWs}$ for $\mathrm{CH}_{4}$ concentrations of $(\mathbf{a}, \mathbf{b})$ 10, (c,d) 20, (e,f) 30, and (g,h) $40 \mathrm{sccm}$.

The oxidation of the as-grown Cu-NW and $20 \mathrm{sccm} \mathrm{CH}_{4} \mathrm{G} / \mathrm{Cu}-\mathrm{NW}$ samples (before and after oxidation) could be determined from the XRD spectra (Figure 4). Figure 4a shows the total XRD data of the samples from 20 to 80 degrees. The general Cu peaks of (111), (200), and (220) are apparent at approximately 44,52 , and 76 degrees, respectively. The G/Cu-NW had higher $\mathrm{Cu}$ intensity than the as-grown $\mathrm{Cu}-\mathrm{NW}$, indicating that the former had higher crystallinity and that the natural oxidation groups of the $\mathrm{Cu}-\mathrm{NW}$ were removed by the graphene growth. Figure $3 \mathrm{~b}, \mathrm{c}$ show the cuprous oxide $\left(\mathrm{Cu}_{2} \mathrm{O}\right)$ and cupric oxide $(\mathrm{CuO})$ peaks of the samples. For the as-grown $\mathrm{Cu}-\mathrm{NW}$, the $\mathrm{Cu}_{2} \mathrm{O}$ peaks were observed at approximately 36 and 42 degrees, and the $\mathrm{CuO}$ peaks were observed at approximately 39 , 61 , and 74 degrees. However, $\mathrm{Cu}_{2} \mathrm{O}$ and $\mathrm{CuO}$ peaks were not observed for the $\mathrm{G} / \mathrm{Cu}-\mathrm{NW}$ before or after the oxidation process. These results agree with Figure 3, in that they indicate good graphene step coverage without oxidation of the $\mathrm{Cu}-\mathrm{NW}$ in the $\mathrm{G} / \mathrm{Cu}-\mathrm{NW}$ prepared using $20 \mathrm{sccm} \mathrm{CH}_{4}$. These results also indicate that the graphene prevented $\mathrm{Cu}$ oxidation.

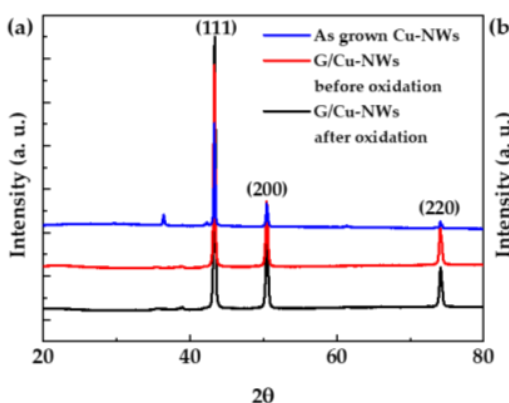

$2 \theta$

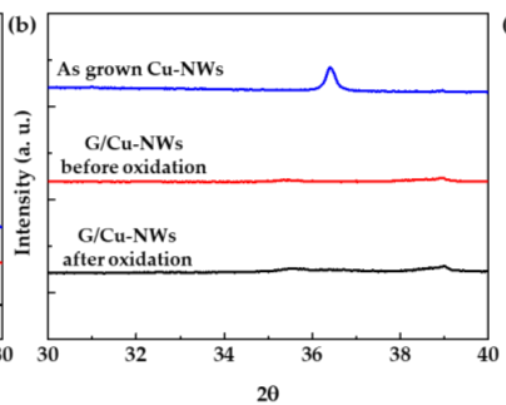

$2 \theta$

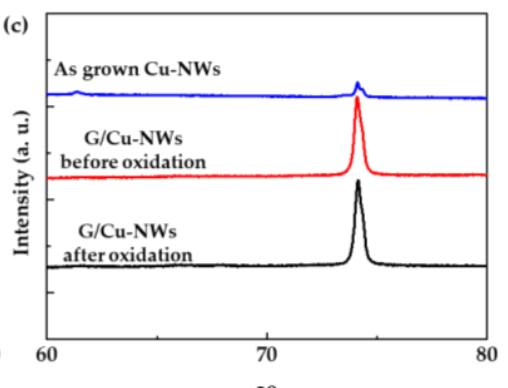

Figure 4. XRD spectra of as-grown $\mathrm{Cu}-\mathrm{NW}$ and $20 \mathrm{sccm}-\mathrm{CH}_{4} \mathrm{G} / \mathrm{Cu}-\mathrm{NW}$ before and after oxidation; (a) full XRD spectra, (b) $\mathrm{Cu}_{2} \mathrm{O}$ and $\mathrm{CuO}$ peaks, and (c) $\mathrm{CuO}$ peaks.

CNTs were grown on the synthesized G/Cu-NW prepared under $20 \mathrm{sccm} \mathrm{CH}_{4}$ using various $\mathrm{Fe}$ catalyst concentrations. Figure 5 shows the 3DC Cu-NWs grown using Fe catalyst concentrations of $7.5,12.5$, and $17.5 \mathrm{mg} / \mathrm{L}$ and LP-CVD. The CNTs grown with the $7.5 \mathrm{mg} / \mathrm{L}$ Fe catalyst were short (Figure $4 \mathrm{a}, \mathrm{b}$ ), while the CNTs were improperly grown for the $17.5 \mathrm{mg} / \mathrm{L} \mathrm{Fe}$ catalyst (Figure $5 \mathrm{e}, \mathrm{f}$ ). 
However, the CNTs were well grown with the $12.5 \mathrm{mg} / \mathrm{L} \mathrm{Fe}$ catalyst concentration (Figure $5 \mathrm{c}, \mathrm{d}$ ); thus, the $12.5 \mathrm{mg} / \mathrm{L}$ was an appropriate Fe concentration for the CNT growth on the prepared Cu-NW. Furthermore, the largest specific surface area was obtained for the CNT grown using the $12.5 \mathrm{mg} / \mathrm{L} \mathrm{Fe}$ catalyst. It was therefore apparent that the 3DC Cu-NW grown using the $12.5 \mathrm{mg} / \mathrm{L} \mathrm{Fe}$ catalyst could potentially be used to enhance the electrochemical properties of the IPMC. Figure $5 \mathrm{~g}$ schematically illustrates the growth process from $\mathrm{Cu}-\mathrm{NW}$ to $3 \mathrm{DC} \mathrm{Cu}-\mathrm{NW}$, according to the corresponding structures.

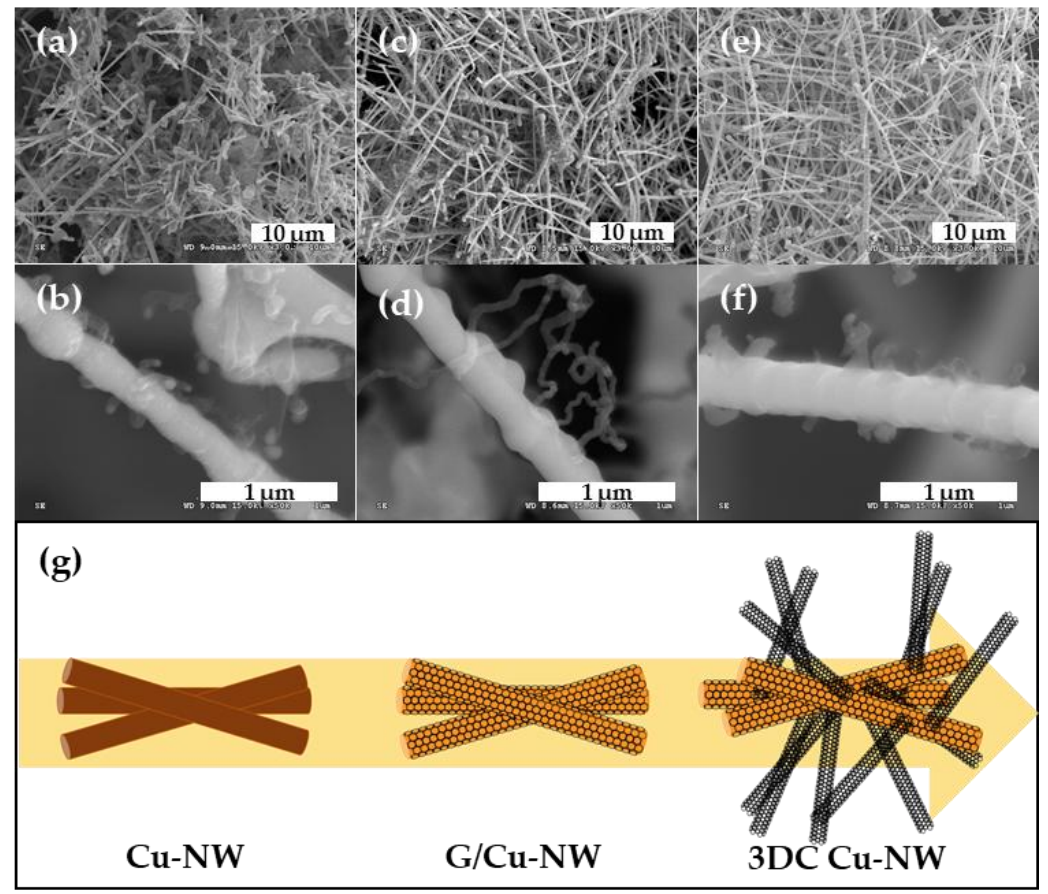

Figure 5. SEM images of carbon nanotubes (CNT) growth for Fe catalyst concentrations of $(\mathbf{a}, \mathbf{b}) 7.5,(\mathbf{c}, \mathbf{d})$ 12.5 , and $(\mathbf{e}, \mathbf{f}) 17.5 \mathrm{mg} / \mathrm{L} ;(\mathbf{g})$ Schematic diagram of structural changes from Cu-NW to 3DC Cu-NW.

Figure 6 shows the FT-IR spectra of the G/Cu-NW and 3DC Cu-NW prepared using the 12.5 $\mathrm{mg} / \mu \mathrm{L}$ Fe catalyst. For both specimen types, peaks corresponding to the $\mathrm{O}-\mathrm{H}$ stretching vibration, $\mathrm{C}-\mathrm{H}$ asymmetric and symmetric $\mathrm{CH}_{2}$ stretching vibration, $\mathrm{C}=\mathrm{O}$ stretching vibration, and $\mathrm{C}=\mathrm{C}$ skeletal vibration of graphitic domains were observed at approximately 3430 and 3435, from 2852 to 2924,1746 and $1748,1633 \mathrm{~cm}^{-1}$, respectively [30-33]. N-H bend vibration (at $1545 \mathrm{~cm}^{-1}$ ) was only observed at $\mathrm{G} / \mathrm{Cu}-\mathrm{NWs}$. Note that the N-H group appeared because EDA with an amine group was used in the $\mathrm{Cu}-\mathrm{NW}$ synthesis. After the CNTs were grown on the G/Cu-NW, the intensities of the carbon groups increased, and the intensity of $\mathrm{N}-\mathrm{H}$ bend vibration reduced because of CNT growth on G/Cu-NW [34,35]. Also, C-O stretching vibration (at $1462 \mathrm{~cm}^{-1}$ ) and C-O stretching vibration (1262 $\mathrm{cm}^{-1}$ ) were created. This means that the 3DC Cu-NW had many functional groups on its surface compared to the G/Cu-NW. Note that various graphene and CNT functional groups help improve the electrical and chemical properties of the material. 


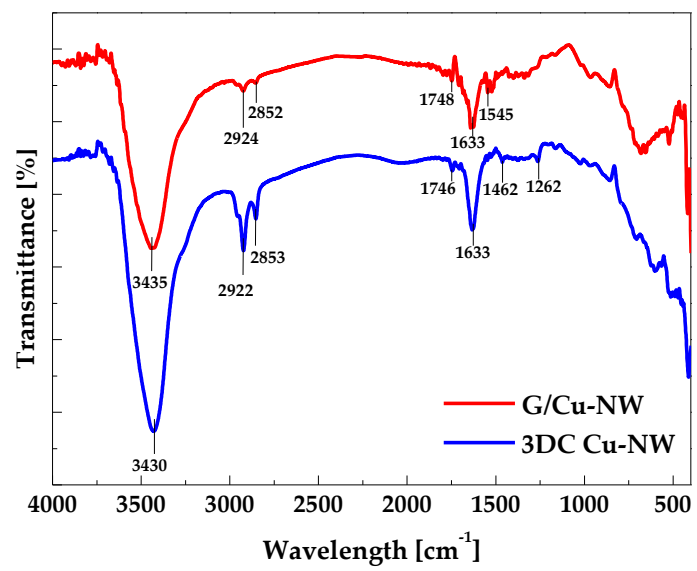

Figure 6. FT-IR spectra of G/Cu-NW and 3DC Cu-NW.

\subsection{Characteristics of the IPMC Actuator Based on 3DC Cu-NW}

An IPMC actuator based on a GO/Ag-NW electrode with an interface layer was fabricated. The 3DC Cu-NW prepared using $12.5 \mathrm{mg} / \mathrm{L}$ Fe catalyst was used as the IPMC interface layer between the Nafion and the electrode. To observe the electrochemical properties of the IPMC actuator, 0.2, 0.4, and $0.6 \mathrm{wt} \%$ 3DC Cu-NW samples were used as interface layers. The electrochemical properties of the IPMC actuator were measured under $\pm 0.5 \mathrm{~V}$, at a scan rate of $50 \mathrm{mV} / \mathrm{s}$, and current range of $10 \mathrm{~mA}$ in $\mathrm{LiCl}$ solution. Figure 7 shows the electrochemical properties recorded for actuators with 0 to 0.6 $w t \% 3$ DC Cu-NW content. Figure 7a shows the current density of the IPMC actuator, which increased with increasing 3DC Cu-NW concentration. Figure $7 \mathrm{~b}$ shows the current-voltage $(I-V)$ curve of the IPMC actuator. The area of the $I-V$ curve indicates the capacitance of the IPMC actuator; these results are shown in Figure 7c. From these graphs, it is apparent that the IPMC actuator with $0.6 \mathrm{wt} \%$ 3DC $\mathrm{Cu}-\mathrm{NW}$ had superior electrochemical properties to the other specimens. Importantly, this result means that the IPMC actuator with the 3DC Cu-NW interface layer had a greater charge storage than that with no 3DC Cu-NW interface layer.
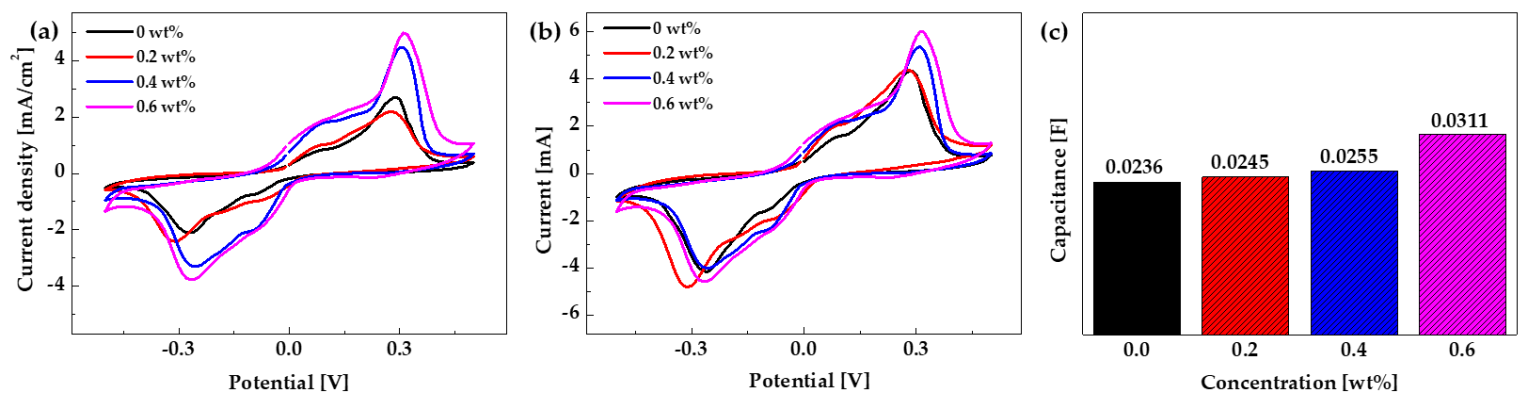

Figure 7. (a) Current density and (b) $I-V$ curves, and (c) capacitance of IPMC actuator according to 3DC Cu-NW concentration.

Figure 8a-d show the cross sections of each IPMC actuator according to the 3DC Cu-NW concentration. The Nafion membrane and electrode were well attached in all IPMC actuators with a 3DC Cu-NW interface layer. However, poor attachment of these components was observed for the IPMC actuator without the 3DC Cu-NW interface layer. To observe the actuation characteristics, an AC voltage was injected into the IPMC actuators with 3DC Cu-NW. The DC voltage was 0 to $2.5 \mathrm{~s}$ at 1 $\mathrm{V}_{\mathrm{DC}}$. The actuation performances of the IPMC actuators with different 3DC Cu-NW concentrations are shown in Figure 8e,f. Figure 8e shows the displacement performance according to time under 1 $\mathrm{V}_{\mathrm{AC}}$ and $0.2 \mathrm{~Hz}$. There were notable increases in displacement for the IPMC actuators with more than $0.4 \mathrm{wt} \% 3 \mathrm{DC} \mathrm{Cu}-\mathrm{NW}$, with the largest displacement being obtained for the IPMC actuator with 0.6 
$w t \%$ 3DC Cu-NW. Figure 8f shows the real-time displacement values for the IPMC actuators at $2.5 \mathrm{~s}$ after $1 \mathrm{~V}_{\mathrm{DC}}$ input. The displacement of the IPMC actuator with $0.6 \mathrm{wt} \%$ 3DC Cu-NW was larger than those of the others at $2.5 \mathrm{~s}$; thus, this actuator had a higher response rate. Hence, we observed that the newly fabricated 3DC Cu-NW had the potential to enhance the electrochemical properties and actuation performance of the IPMC actuator, with $0.6 \mathrm{wt} \% 3 \mathrm{DC} \mathrm{Cu}-\mathrm{NW}$ content giving the best results.
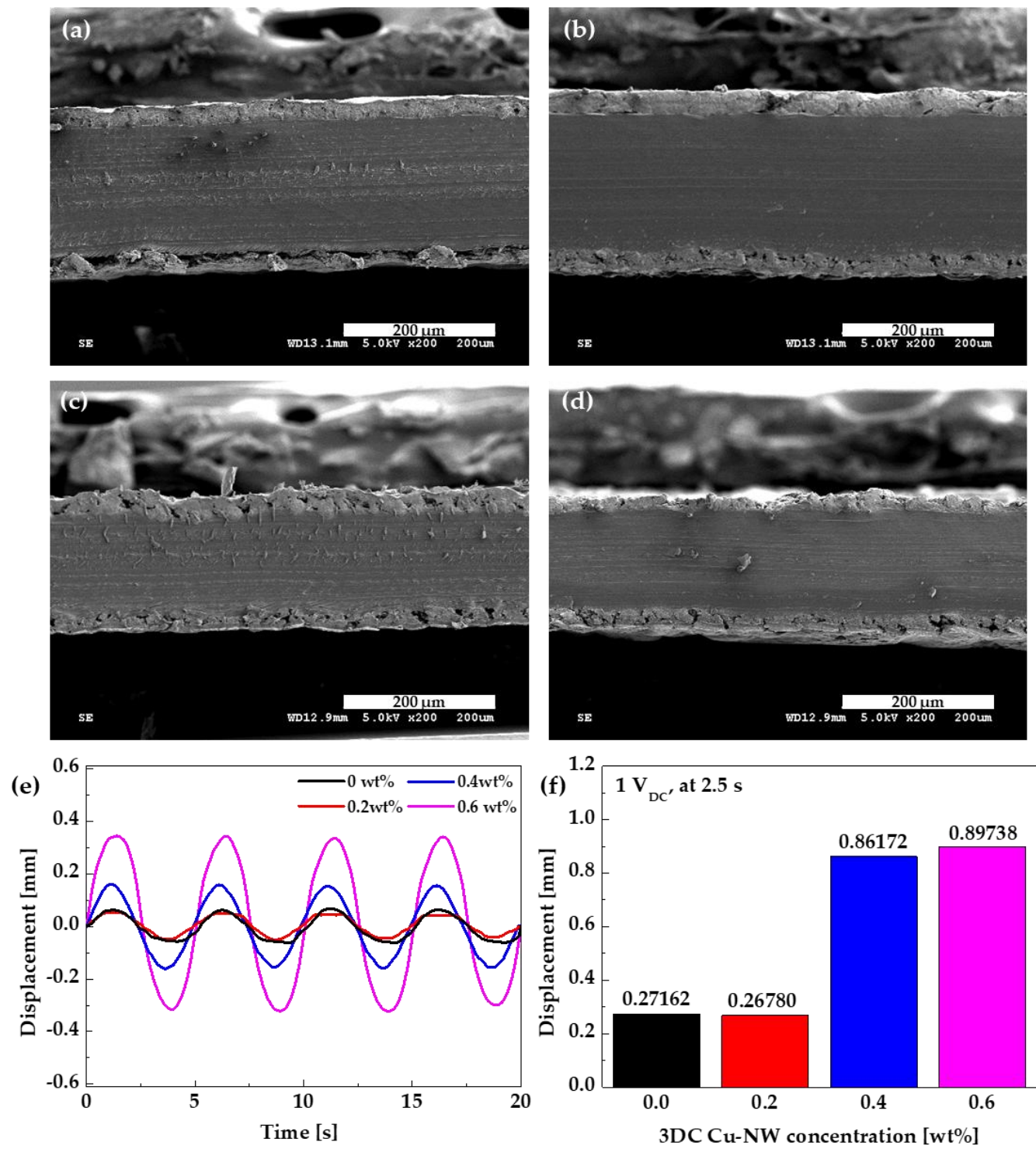

Figure 8. Cross sections of IPMC actuators with (a) 0 , (b) 0.2 , (c) 0.4 , and (d) $0.6 \mathrm{wt} \%$ 3DC Cu-NW; (e) Displacement vs. time $\left( \pm 1 \mathrm{~V}_{\mathrm{AC}}, 0.2 \mathrm{~Hz}\right)$, and (f) real-time displacement at $2.5 \mathrm{~s}$ under $1 \mathrm{~V}_{\mathrm{DC}}$ results for IPMC actuators according to 3DC Cu-NW concentration.

\section{Conclusions}

3DC Cu-NW with a new structure was synthesized in this study and employed as an interface layer in an IPMC actuator. The 3DC Cu-NW used in this device had an average diameter of approximately $362 \mathrm{~nm}$. We successfully synthesized 3DC Cu-NWs with different properties according to their $\mathrm{CH}_{4}$ and Fe catalyst concentrations by using an LP-CVD system to prevent oxidation of the Cu-NW. The Cu-NW, G/Cu-NW, and 3DC Cu-NW growth steps were each optimized by considering SEM and FT-IR results. The morphology of the 3DC Cu-NW was well preserved, and it was confirmed that Cu oxidation did not occur. The fabricated IPMC actuator with a 3DC Cu-NW interface layer varied according to the 3DC Cu-NW concentration. The current density and capacitance were increased according 
to the added 3DC Cu-NW, which had a large specific surface area. In particular, the capacitance, displacement, and response rate of the IPMC actuator with $0.6 \mathrm{wt} \%$ 3DC Cu-NW were 1.3, 5.6, and 3.3 times higher than those of an IPMC actuator with no 3DC Cu-NW, respectively. Thus, the fabricated 3DC Cu-NW has potential as an interface material for an IPMC actuator. Furthermore, the synthesis technology used to prepare the newly structured 3DC Cu-NW with a large specific surface area could promote applications involving carbon-based devices, flexible actuators, and electrochemical sensors.

Author Contributions: Experiments, data analysis, and writing-original draft preparation, S.P.; Initial idea, writing - and editing and data curation, M.P.; experimental data curation and validation, S.K.; project administration, writing — review and editing, M.J. All authors have read and agreed to the published version of the manuscript.

Funding: This research was supported by a grant to Bio-Mimetic Robot Research Center Funded by Defense Acquisition Program Administration, and by Agency for Defense Development (UD190018ID).

Conflicts of Interest: The authors declare no conflict of interest.

\section{References}

1. Wang, J.; Li, J.; Xu, Z.; Wang, S.; Wang, Z.; Xu, B.; Sun, Y.; Liu, S.; Zhao, H. Design, analysis, experiments and kinetic model of a high step efficiency piezoelectric actuator. Mechatronics 2019, 59, 61-68. [CrossRef]

2. Zhang, Q.M.; Wang, H.; Zhao, J. Effect of driving field and temperature on the response behavior of ferroelectric actuator and sensor materials. J. Intell. Mater. Syst. Struct. 1995, 6, 84-93. [CrossRef]

3. Mehrabi, H.; Aminzahed, I. Design and testing of a microgripper with SMA actuator for manipulation of micro components. Microsyst. Technol. 2019, 26, 531-536. [CrossRef]

4. Loeian, M.S.; Ziolkowska, D.A.; Khosravi, F.; Jasinski, J.B.; Panchapakesan, B. Exfoliated $\mathrm{WS}_{2}-\mathrm{Nafion}$ Composite based Electromechanical Actuators. Sci. Rep. 2017, 7, 14599. [CrossRef] [PubMed]

5. Fan, X.; Khosravi, F.; Rahneshin, V.; Shanmugam, M.; Loeian, M.; Jasinski, J.; Chon, R.W.; Terentjev, E.; Panchapakesan, B. $\mathrm{MoS}_{2}$ actuators: Reversible mechanical responses of $\mathrm{MoS}_{2}$-polymer nanocomposites to photons. Nanotechnology 2015, 26, 261001. [CrossRef] [PubMed]

6. Loomis, J.; Fan, X.; Khosravi, F.; Xu, P.; Fletcher, M.; Cohn, R.W.; Panchapakesan, B. Graphene/elastomer composite-based photo-thermal nanopositioners. Sci. Rep. 2013, 3, 1900. [CrossRef] [PubMed]

7. Loomis, J.; King, B.; Burkhead, T.; Xu, P.; Bessler, N.; Terentjev, E.; Panchapakesan, B. Graphene-nanoplatelet-based photomechanical actuators. Nanotechnology 2012, 23, 045501. [CrossRef]

8. Shi, L.; Guo, S. Development and Evaluation of a Venus Flytrap-Inspired Microrobot Microsyst. Technology 2016, 22, 1949-1958.

9. Shahinpoor, M.; Kim, K.J. Ionic polymer-metal composites: IV. Industrial and medical applications. Smart Mater. Struct. 2004, 14, 197. [CrossRef]

10. Zhang, W.; Gu, Y.; Mou, J. Recent Developments About IPMCs (Ionic Polymer-Metal) Composites: A Review of Performances for Different Conditions. Fluid Dyn. Mater. Process. 2018, 14, 243-258. [CrossRef]

11. Bhandari, B.; Lee, G.Y.; Ahn, S.H. A review on IPMC material as actuators and sensors: Fabrications, characteristics and applications. Int. J. Precis. Eng. Manuf. 2012, 13, 141-163. [CrossRef]

12. Chung, C.K.; Fung, P.K.; Hong, Y.Z.; Ju, M.S.; Lin, C.C.K.; Wu, T.C. A novel fabrication of ionic polymer-metal composites (IPMC) actuator with silver nano-powders. Sens. Actuators B Chem. 2006, 117,367-375. [CrossRef]

13. Bian, K.; Liu, H.; Tai, G.; Zhu, K.; Xiong, K. Enhanced actuation response of nafion-based ionic polymer metal composites by doping $\mathrm{BaTiO}_{3}$ nanoparticles. J. Phys. Chem. C 2016, 120, 12377-12384. [CrossRef]

14. Jung, J.H.; Jeon, J.H.; Sridhar, V.; Oh, I.K. Electro-active graphene-Nafion actuators. Carbon 2011, 49, 1279-1289. [CrossRef]

15. Guo, D.J.; Liu, R.; Cheng, Y.; Zhang, H.; Zhou, L.M.; Fang, S.M.; Elliott, W.H.; Tan, W. Reverse adhesion of a gecko-inspired synthetic adhesive switched by an ion-exchange polymer-metal composite actuator. ACS Appl. Mater. Interfaces 2015, 7, 5480-5487. [CrossRef]

16. Lian, H.; Qian, W.; Estevez, L.; Liu, H.; Liu, Y.; Jiang, T.; Wanga, W.G.; Guoe, W.; Giannelis, E.P. Enhanced actuation in functionalized carbon nanotube-Nafion composites. Sens. Actuators B Chem. 2011, 156, 187-193. [CrossRef] 
17. Lee, P.C.; Hyun, J.E.; Jeoung, S.K.; Nam, J.D.; Hwang, T.; Kim, K.J.; Solasa, K.C. Ionic polymer metal composites for use as an organic electrolyte supercapacitor. Smart Mater. Struct. 2019, 28, 054003. [CrossRef]

18. Jung, Y.; Kim, S.J.; Kim, K.J.; Lee, D.Y. Characteristics of ionic polymer-metal composite with chemically doped $\mathrm{TiO}_{2}$ particles. Smart Mater. Struct. 2011, 20, 124004. [CrossRef]

19. Bhanushali, S.; Ghosh, P.; Ganesh, A.; Cheng, W. 1D copper nanostructures: Progress, challenges and opportunities. Small 2015, 11, 1232-1252. [CrossRef]

20. Ye, S.; Rathmell, A.R.; Stewart, I.E.; Ha, Y.C.; Wilson, A.R.; Chen, Z.; Wiley, B.J. A rapid synthesis of high aspect ratio copper nanowires for high-performance transparent conducting films. Chem. Commun. 2014, 50, 2562-2564. [CrossRef]

21. Chang, Y.; Lye, M.L.; Zeng, H.C. Large-scale synthesis of high-quality ultralong copper nanowires. Langmuir 2005, 21, 3746-3748. [CrossRef] [PubMed]

22. Ahn, Y.; Jeong, Y.; Lee, D.; Lee, Y. Copper nanowire-graphene core-shell nanostructure for highly stable transparent conducting electrodes. ACS Nano 2015, 9, 3125-3133. [CrossRef] [PubMed]

23. Wu, S.; Zou, M.; Li, Z.; Chen, D.; Zhang, H.; Yuan, Y.; Pei, Y.; Cao, A. Robust and Stable Cu Nanowire@ Graphene Core-Shell Aerogels for Ultraeffective Electromagnetic Interference Shielding. Small 2018, 14, 1800634. [CrossRef] [PubMed]

24. Xu, H.; Wang, H.; Wu, C.; Lin, N.; Soomro, A.M.; Guo, H.; Liu, C.; Yang, X.; Wu, Y.; Cai, D.; et al. Direct synthesis of graphene 3D-coated $\mathrm{Cu}$ nanosilks network for antioxidant transparent conducting electrode. Nanoscale 2015, 7, 10613-10621. [CrossRef]

25. Mehta, R.; Chugh, S.; Chen, Z. Enhanced electrical and thermal conduction in graphene-encapsulated copper nanowires. Nano Lett. 2015, 15, 2024-2030. [CrossRef]

26. Kim, J.; Bae, S.H.; Kotal, M.; Stalbaum, T.; Kim, K.J.; Oh, I.K. Soft but Powerful Artificial Muscles Based on 3D Graphene-CNT-Ni Heteronanostructures. Small 2017, 13, 1701314. [CrossRef]

27. Park, M.; Ahn, S.K.; Hwang, S.; Park, S.; Kim, S.; Jeon, M. Synthesis of Nitrogen-Doped Graphene on Copper Nanowires for Efficient Thermal Conductivity and Stability by Using Conventional Thermal Chemical Vapor Deposition. Nanomaterials 2019, 9, 984. [CrossRef]

28. Yoo, S.; Park, M.; Kim, S.; Chung, P.S.; Jeon, M. Graphene Oxide-Silver Nanowires Paper Electrodes with Poly (3, 4-ethylenedioxythiophene)-Poly (styrenesulfonate) to Enhance the Driving Properties of Ionic Electroactive Polymer Actuators. Nanosci. Nanotechnol. Lett. 2018, 10, 1107-1112. [CrossRef]

29. Park, M.; Kim, J.; Song, H.; Kim, S.; Jeon, M. Fast and Stable Ionic Electroactive Polymer Actuators with PEDOT:PSS/(Graphene-Ag-Nanowires) Nanocomposite Electrodes. Sensors 2018, 18, 3126. [CrossRef]

30. Geng, D.; Yang, S.; Zhang, Y.; Yang, J.; Liu, J.; Li, R.; Sham, T.-K.; Sun, X.; Ye, S.; Knights, S. Nitrogen doping effects on the structure of graphene. Appl. Surf. Sci. 2011, 257, 9193-9198. [CrossRef]

31. Li, L.; Dou, Y.; Wang, L.; Luo, M.; Liang, J. One-step synthesis of high-quality N-doped graphene/Fe $3 \mathrm{O}_{4}$ hybrid nanocomposite and its improved supercapacitor performances. RSC Adv. 2014, 4, 25658-25665. [CrossRef]

32. Balaji, S.S.; Elavarasan, A.; Sathish, M. High performance supercapacitor using N-doped graphene prepared via supercritical fluid processing with an oxime nitrogen source. Appl. Surf. Sci. 2013, 266, 360-367. [CrossRef]

33. Yadav, S.K.; Cho, J.W. Functionalized graphene nanoplatelets for enhanced mechanical and thermal properties of polyurethane nanocomposites. Cogent Eng. 2015, 2, 1094017. [CrossRef]

34. Mani, V.; Chen, S.M.; Lou, B.S. Three dimensional graphene oxide-carbon nanotubes and graphene-carbon nanotubes hybrids. Int. J. Electrochem. Sci. 2013, 8, e60.

35. Zhoua, N.; An, Q.; Xiaoa, Z.; Zhai, S.; Shi, Z. Solvothermal synthesis of three-dimensional, $\mathrm{Fe}_{2} \mathrm{O}_{3}$ NPs-embedded CNT/N-doped graphene composites with excellent microwave absorption performance. RSC Adv. 2017, 7, 45156-45169. [CrossRef]

(C) 2020 by the authors. Licensee MDPI, Basel, Switzerland. This article is an open access article distributed under the terms and conditions of the Creative Commons Attribution (CC BY) license (http://creativecommons.org/licenses/by/4.0/). 